\title{
Rechtsgeschichte
}

\section{Tomasz Giaro}

\section{Traditionswerkstatt Rechtsgeschichte}


werden sollte, die gemeinsamen Grundlagen eines europäischen Privatrechts seien auch in Schottland auszumachen, darf man daher den Erfolg dieses Unternehmens bezweifeln: Wer schon daran glaubte, musste nicht erst überzeugt werden; wer aber noch nicht überzeugt war, der wird auch durch dieses Werk nicht umgestimmt werden.

\section{Traditionswerkstatt Rechtsgeschichte*}

Zimmermanns drei Clarendon lectures erörtern die Emanzipation der deutschen Romanistik von der Pandektistik unter dem Einfluss des BGB ( $\mathrm{I}-52)$, die trotzdem fortdauernde Verwurzelung der Zivilistik im römischen Recht (53-I05) und die europäische Natur der heutigen nationalen Privatrechte (IO7-I 85 ). Zimmermann widmet die erste Vorlesung der Vergangenheit, die zweite der Gegenwart, die dritte der Zukunft (XX), doch hat man es eher durchgehend mit einer Mixtur von Rechtsgeschichte, Rechtsdogmatik, Rechtsvergleichung und Rechtspolitik zu tun. Es geht ihm nämlich darum, durch eine gemeineuropäische Rekonstitution der deutschen Historischen Rechtsschule das Bewusstsein einer »intellectual unity created by a common tradition " als Vorbedingung der Europäisierung des Privatrechts wieder aufzubauen (XIX f.). Die Anrufung des Savigny-Erbes folgt der rechtshistorischen Gepflogenheit, $\mathrm{Zu}$ kunftsentwürfe als revivals $\mathrm{zu}$ gestalten und gegenwärtige Diskurse mit dem scholastischen Autoritätsargument abzuschneiden.

Die erste Vorlesung The End of an Era: Transformation of Scholarship in Roman Law, eine Übersetzung des Beitrags für den Sammelband »Rechtsgeschichte und Privatrechtsdogmatik « (Heidelberg I999, I-39), schildert das kodifikationsbedingte Auseinanderleben von
Romanistik und Zivilistik. Wohl aus Versehen schiebt Zimmermann dabei Entstellungen des römischen Rechts dem mos gallicus statt dem italicus in die Schuhe (I 8). Infolge der »historicization of legal history « (40) durch Otto Lenel, Ludwig Mitteis, Emil Seckel und deren Schüler sei die heutige legal scholarship, also die gesamte Rechtswissenschaft, "completely a-historical « geworden (II, $22 \mathrm{ff}$.). Dieses sensationelle Ergebnis verdankt sich nur Zimmermanns anachronistischer Terminologie. Konnten doch jene Gelehrten so lange keine Historisierung der legal history vornehmen, wie diese im Schatten der Pandektistik kein autonomes Fach gewesen ist. Auf demselben quid pro quo beruht der Tadel des Ahistorismus der heutigen Rechtswissenschaft. Denn ahistorisch ist allein die von der Rechtsgeschichte getrennte Dogmatik oder Zivilistik geworden. Durch diese Ausdifferenzierung der Pandektenjurisprudenz entstand aber erst das moderne System der Rechtswissenschaft. Die Frage, inwieweit seine Binnengrenzen zu lockern seien, ist mit Aufrufen zur Wiederherstellung der Vergangenheit nicht zu lösen.

Die zweite Vorlesung The Transition from Civil Law to Civil Code in Germany: Dawn of a New Era? bestreitet mit Windscheid (I7) die Rolle des BGB als Zäsur der Rechtsgeschichte. Gegen den Gemeinplatz, die Rechtsprechung des

\footnotetext{
* Reinhard Zimmermann, Roman Law, Contemporary Law, European Law. The Civilian Tradition Today, Oxford: Oxford University Press 200I, XX, I97 S., ISBN O-I 9-829913-3
} 
Reichsgerichts in den ersten zwei Dekaden der BGB-Geltung sei extrem positivistisch gewesen, verteidigt Zimmermann ihre Unabhängigkeit vom Gesetz, besonders im Deliktsrecht, wo sie die früheren Trends fortsetzte $(56,78 \mathrm{ff}$.). Da auch die übrige Judikatur "an overwhelming sense of continuity « vermittle, sei das deutsche Recht mit dem BGB als "transitional stage " seiner Tradition "firmly anchored in the ius commune which in turn is based on Roman law " (98, Ioo f.). Diese Voraussetzung rechtfertige die von Rabel praktizierte und von Koschaker theoretisierte Synthese der voreilig auseinander gedachten Fächer Rechtsgeschichte und Rechtsdogmatik (IO3 f.). Tragen aber diese bejahrten Autoritäten die Kehrtwendung zu den vorkodifikatorischen Zuständen? Wer glaubt, dass damit der Rechtsgeschichte gedient sei, nimmt die traditionelle Lehrstuhlkopplung, der zufolge ein Zivilist auch der beste Rechtshistoriker sein müsse und umgekehrt, wissenschaftlich für bare Münze. Die Rechtsgeschichte wie eine ertappte serva fugitiva ihren privatrechtlichen Dienstbarkeiten zurückzugeben würde ihre inzwischen verfestigte Rolle als Partnerin der Rechtsphilosophie, -theorie und -soziologie sowie der Disziplinen des öffentlichen Rechts und der Geschichtswissenschaft untergraben.

Die dritte Vorlesung A Change in Perspective: European Private Law and its Historical Foundations gilt unserem »age of post-positivism «, das der Dichotomie von civil und common law zuwider auf Grund der western legal tradition ein neues ius commune anstrebe (Io9 ff.). Mit der ersehnten Vermischung der beiden alten Systeme im Blick erörtert der Autor die mixed systems Südafrikas und Schottlands, um munter $a b$ posse ad esse zu schließen, dass Europas Rechte schon jetzt gemischt sind
(I 26 ff., I 59). Beweise? Die Präsenz des Testamentsvollstreckers auf dem Kontinent sowie die Tatsache, dass weder der trust ein Spezifikum des common law noch der gute Glaube ein solches des civil law ist ( $160 \mathrm{ff}$.). Und selbst wenn ersteres überwiegend Richterrecht und letzteres Kodexrecht seien, werde dies von der ubiquitären Relevanz der Präzedentien und von den Ähnlichkeiten der Gesetzesauslegung relativiert (I $77 \mathrm{ff}$.). In einem derart relativistischen Geist kaschiert der Autor, der das BGB entweder als "supreme triumph « oder als »ultimate failure « der Historischen Rechtsschule ansieht (XX), die »interesting diversity " von common und civil law durch die "fundamental intellectual unity « der western legal tradition, ebenso wie er das Räuberopfer aus der Geschichte vom barmherzigen Samariter im Lukasevangelium eher halb lebendig als tot wissen möchte ( $188 \mathrm{f}$.).

Das nachpositivistische Rechtsdenken in Traditionen entlastet offensichtlich von Präzision. So erfährt man kaum etwas über die territoriale Ostgrenze der western legal tradition und man hat nicht den Eindruck, dass diese wie bei H. J. Berman (Recht und Revolution, Frankfurt a.M. I99I, 820f.) auch Osteuropa einschließlich Russland umfasst. Eine andere von der Tradition als Vergangenheit mit einer gegenwärtig verpflichtenden Kraft (H. P. Glenn, Legal Traditions of the World, Oxford 2000, I I, 323) verwischte Grenze ist die zwischen Rechtsgeschichte und Rechtsdogmatik (E. Picker, Rechtsdogmatik und Rechtsgeschichte, AcP 20I, 200I, 763 ff., 805 ff.). Im Zeitalter der Dekodifikation müssen Traditionen als vom juristischen Positivismus vernachlässigter Kern von Rechtskulturen herhalten. Soll aber gerade der Rechtshistoriker Traditionen frönen?

Tomasz Giaro 